ISSN 1112-9867

\title{
EFFECTS OF MAGNESIUM SULFATE ON THE ACQUISITION AND REINSTATEMENT OF MORPHINE-INDUCED CONDITIONED PLACE PREFERENCE IN MICE
}

\author{
A. Mahmoud Hashemzaei ${ }^{1}$, B. Saeed Keykha ${ }^{1}$, C. Fatemeh Shahraki ${ }^{2}$, D. Amirhooshang \\ Mohammadpour ${ }^{3}$ and E. Kaveh Tabrizian ${ }^{1, *}$ \\ ${ }^{1}$ Department of Pharmacology and Toxicology, Faculty of Pharmacy, Zabol University of \\ Medical Sciences, Zabol, Iran \\ ${ }^{2}$ Student of veterinary medicine, faculty of veterinary, university of zabol, Iran \\ ${ }^{3}$ Department of Clinical Pharmacy, Faculty of Pharmacy, Mashhad University of Medical \\ Sciences, Mashhad, Iran \\ *Correspondence: K. tabrizian, Department of Pharmacology and Toxicology, Faculty of \\ Pharmacy, Zabol University of Medical Sciences, Zabol, Iran
}

Published online: 05 June 2016

\begin{abstract}
Relapse to opioid, even long time after withdrawal, is one of the most important problems of opiate withdrawal programs. Magnesium has been shown that; inhibit glutamate release and induces N-Methyl-D-aspartate (NMDA) antagonistic effects; moreover, glutamate NMDA antagonists contribute to the reinforcement of morphine. In the current study, the effects of magnesium sulfate on the acquisition and reinstatement of morphine-induced conditioned place preference (CPP) in an animal model were investigated. The acquisition and extinction and reinstatement phases induced using morphine 40 and $10 \mathrm{mg} / \mathrm{kg}$.
\end{abstract}

Author Correspondence, e-mail: ntoxicologist@gmail.com

doi: http://dx.doi.org/10.4314/jfas.8vi2s.7 
Magnesium sulfate 300 and $600 \mathrm{mg} / \mathrm{kg}$ (not $150 \mathrm{mg} / \mathrm{kg}$ ) reduced morphine dependence. Additionally, tendency of animals to the white compartment of CPP chamber significantly decreased. Magnesium sulfate inhibits morphine tendency and reinstatement probably via NMDA antagonistic effects.

Keywords: magnesium sulfate; morphine; conditioned place preference.

\section{INTRODUCTION}

Morphine and other opioids are still the most effective painkillers, especially for postoperative and neuropathic cancer pain [1]. Continuous use of opioids and dependence on these medications are increasing among individuals around the world. Additionally, abstinence-based treatments are normally interrupted, following opioid withdrawal $[1,2]$.

Relapse to opioid use is one of the most important problems after morphine withdrawal. In fact, relapse is a subjective sensation that can motivate individuals to seek drugs even after long periods of abstinence.

Amongst multiple neurotransmitter systems (including dopaminergic, GABAergic, glutamatergic, serotonergic, and adrenergic systems) and endogenous opioid peptides, dopaminergic system is the most important involved system in morphine withdrawal [3, 4]. Dopaminergic neurons of ventral tegmental area (VTA), reaching the nucleus accumbens (NAcc), can induce natural rewarding and electrical stimulation [3].

Following the activation of dopaminergic neurons, the inhibitory effects of GABAergic interneurons in the VTA are removed, leading to an increase in dopaminergic firing in the NAcc. In fact, when VTA is activated by morphine, it can increase dopamine transmission by suppressing GABAergic interneuron projection into NAcc [5].

According to previous studies, some dopamine antagonists including haloperidol, clozapine, risperidone, and SCH 23390 can inverse morphine tendency in CPP method [6-9]. This is not the only mechanism of the rewarding system, but prefrontal cortex and limbic system project toward VTA and NAcc and control the release of dopamine via glutamate and N-methyl-D-aspartate (NMDA) receptors. In fact, memantine (an NMDA receptor antagonist) leads to the acquisition of morphine-induced CPP [4].

Magnesium, which is found in all parts of the brain, is the second most abundant intracellular cation, involved in many brain physiological processes [10]. This element has been used in 
obstetrics and cardiology for a long time [10-12]. Furthermore, use of magnesium for the treatment of many medical conditions including brain injuries, hypoxia, and ischemia has been widely investigated $[10,13]$.

Magnesium has been shown to play an important role in neuron plasticity [13]. Magnesium deficiency in the brain leads to brain hyperexcitability [13]. Additionally, magnesium can close voltage-dependent calcium channels and result in NMDA antagonistic effects [14]. This element can inhibit the release of excitatory neurotransmitters such as glutamate and potentiate adenosine inhibitory effects on glutamate release in the synapses of central nervous system [15].

As magnesium sulfate has NMDA antagonistic effects and NMDA antagonists show inhibitory effects on morphine relapse, magnesium is assumed to decrease morphine craving after abstinence-based therapy. In other words, magnesium sulfate has antagonistic effects of NMDA receptors and can inhibit glutamate release in the brain. In the current study, for the first time, the efficacy of magnesium sulfate $(150,300$, and $600 \mathrm{mg} / \mathrm{kg}$, i.p.) in decreasing morphine tendency was evaluated in mice in the CPP method.

\section{MATERIALS AND METHODS}

\subsection{Animals}

This study was performed on male NMRI mice (25-30 g), housed under standard conditions (25 ${ }^{\circ} \mathrm{C}$, 12-hour light/12-hour dark cycle) with free access to food and water ad libitum. All experiments were in accordance with animal care guidelines of Zabol University of Medical Sciences.

\subsection{Chemicals}

Morphine sulfate was purchased from Daro-Pakhsh Company, Iran, and magnesium sulfate was provided from Pasteur Institute, Iran.

\subsection{Apparatus}

The apparatus, consisting of three compartments (each $30 \mathrm{~cm}$ in length, $30 \mathrm{~cm}$ in width, and 35 $\mathrm{cm}$ in height), was made of Plexiglas; the compartments could be separated from each other by guillotine doors. When the doors were opened, the mice were allowed to move freely between the compartments; as the doors were closed, the mice were confined in a compartment and were not able to move between the compartments. The two white and black compartments were identical 
in size with different colors, floors, and essences; the roof texture of the white compartment was finer than the black one.

The smell of the white compartment was produced using the essence of banana, in contrast with the black one with an acetic smell. The two compartments were connected by a third graycolored compartment. To avoid any odor interference by animals' feces and/or urine, the compartments were completely cleaned at the end of each experiment.

\subsection{Experimental procedures}

The whole protocol had six different phases including pre-treatment, pre-conditioning, conditioning, post-conditioning, extinction, and reinstatement test (table 1).

Table 1. Treatment schedule for CPP experiment

\begin{tabular}{|l|l|l|l|l|l|}
\hline \multicolumn{2}{|l|}{ Acquisition of CPP } & $\begin{array}{l}\text { The } \\
\text { extinction } \\
\text { phase }\end{array}$ & $\begin{array}{l}\text { The reinstatement } \\
\text { phase }\end{array}$ \\
\hline Pre-treatment & $\begin{array}{l}\text { Pre- } \\
\text { conditioning }\end{array}$ & $\begin{array}{l}\text { Post- } \\
\text { (fourditioning } \\
\text { conditioning } \\
\text { (one day) }\end{array}$ & Seven days & One day \\
\hline Twodays & One day & $\begin{array}{l}\text { Saline+saline, } \\
\text { Saline+morphine40 } \\
\text { mg/kg }\end{array}$ & & $\begin{array}{l}\text { Saline+morphine10 } \\
\mathrm{mg} / \mathrm{kg}\end{array}$ \\
\hline
\end{tabular}

\subsubsection{Pre-conditioning phase}

This phase consisted of three stages. During the first stage, which continued for three days, the animals were familiarized with the boxes. Two days after the beginning of the experiment, the mice were allowed to move freely in all compartments. On the third day, the animals were placed in the compartments for $20 \mathrm{~min}$ and could move freely. The time the mice spent in the compartment was calculated and those spending more than 600 seconds in each compartment were excluded from the experiment.

\subsubsection{Conditioning phase}

The mice were assigned to 8 groups [16]: saline+saline; saline+morphine $40 \mathrm{mg} / \mathrm{kg}$; morphine 40 $\mathrm{mg} / \mathrm{kg}+$ magnesium sulfate 150,300 , and $600 \mathrm{mg} / \mathrm{kg}$; and saline + magnesium sulfate 150,300 , 
and $600 \mathrm{mg} / \mathrm{kg}$ (7 mice per group, 56 mice in total). Following the pre-conditioning phase, the mice received normal saline for 4 consecutive days and were placed in the black compartment apparatus for one hour. Afterwards, the animals were injected either magnesium sulfate or morphine. Then, the mice were placed inside the black compartment for one hour. The selected mice were placed in the white compartment for one hour.

\subsubsection{Post-conditioning phase}

In the third phase (post-conditioning), on the eighth day of the study, the mice were placed in the apparatus with opened doors in a way that they were able to move freely between the chambers. The total time that each mouse spent in any chamber was calculated to be 900 seconds. The time each mouse spent in the middle chamber was equally divided between the two chambers. Differences between the times spent in the pre-conditioning phase and the time in the postconditioning stage for each mouse were calculated. If the calculated time was positive, the drug could induce morphine dependence $[6,17]$.

\subsubsection{Extinction of CPP}

In order to reverse morphine dependency, the animals were placed in the apparatus with open guillotine doors to move freely between the compartments (60 min daily for 7 consecutive days). The time spent in the white compartments could not be significantly different between the preconditioning and extinction phases. The first three phases were similar to the first step of the current experiment. After inducing morphine addiction, the animals were placed in the CPP apparatus for 900 seconds for morphine reinstatement $[6,17]$.

\subsubsection{Reinstatement of CPP}

On day 16, the mice were placed in the CPP apparatus in a way that they could freely move in each compartment and the time was calculated. Afterwards, the animals were injected the remaining dose of morphine $10 \mathrm{mg} / \mathrm{kg}$; thirty minutes later, the animals intraperitoneally received their respective treatments as magnesium sulfate 150,300 , and $600 \mathrm{mg} / \mathrm{kg}$; then, the time spent in the white compartment was determined $[6,17]$. The differences in the time spent in the white compartment before and after the injection were calculated to elucidate if the animals showed reinstatement.

\subsection{Statistical analysis}

One-way ANOVA, followed by Tukey-Kramer post-hoc test, was used for multiple comparisons. Data were presented as mean \pm SEM. P-value $<0.05$ was considered statistically significant. 


\section{RESULTS}

\subsection{Effects of magnesium sulfate on the acquisition of morphine-induced CPP}

Administration of magnesium sulfate $(150,300$, and $600 \mathrm{mg} / \mathrm{kg})$ did not induce CPP or aversion by itself. Magnesium sulfate at doses of 300 and $600 \mathrm{mg} / \mathrm{kg}$ inhibited CPP (Figure 1).

The mice were grouped in the conditioning phase in the drug-paired compartment as follows: SAL (saline plus saline); morphine(saline plus $40 \mathrm{mg} / \mathrm{kg}$ of morphine); $\mathrm{M}+\mathrm{Mg} 150$ (150 mg/kg of magnesium sulfate plus $40 \mathrm{mg} / \mathrm{kg}$ of morphine); $\mathrm{M}+\mathrm{Mg} 300$ (300 mg/kg of magnesium sulfate plus $40 \mathrm{mg} / \mathrm{kg}$ of morphine); $\mathrm{M}+\mathrm{Mg} 600(600 \mathrm{mg} / \mathrm{kg}$ of magnesium sulfate plus 40 $\mathrm{mg} / \mathrm{kg}$ of morphine); Mg 150 (150 mg/kg of magnesium sulfate plus saline); Mg 300 (300 mg/kg of magnesium sulfate plus saline); and $\mathrm{Mg} 600$ (600 mg/kg of magnesium sulfate plus saline).

The bars show the time spent in the drug-paired compartment before conditioning (white bars) and after conditioning sessions (black bars). $\mathrm{P}<0.001$ and $\mathrm{P}<0.01$ showed significant differences in the time spent in the compartments by animals before and after conditioning sessions.

$\square$ Pre Conditioning

Post Conditioning

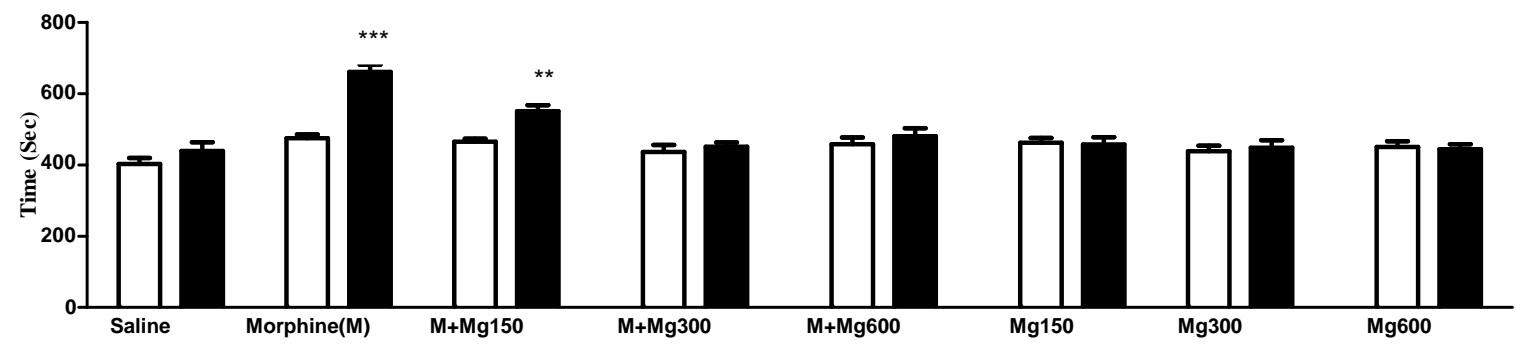

Fig. 1. Effects of magnesium sulfate on morphine-induced CPP

\subsection{Effects of magnesium sulfate on the reinstatement of $\mathrm{CCP}$}

No significant differences were observed between extinction and pre-conditioning phases after daily extinction sessions as the conditioning disappeared. Administration of the priming dose of morphine $(10 \mathrm{mg} / \mathrm{kg})$ reinstated CPP. Magnesium sulfate $600 \mathrm{mg} / \mathrm{kg}$ inhibited the reinstatement of CPP due to the priming dose of morphine (Figure 2$)(* * * \mathrm{P}<0.001$, $* * \mathrm{P}<0.01$ and $* \mathrm{P}<0.05)$. 

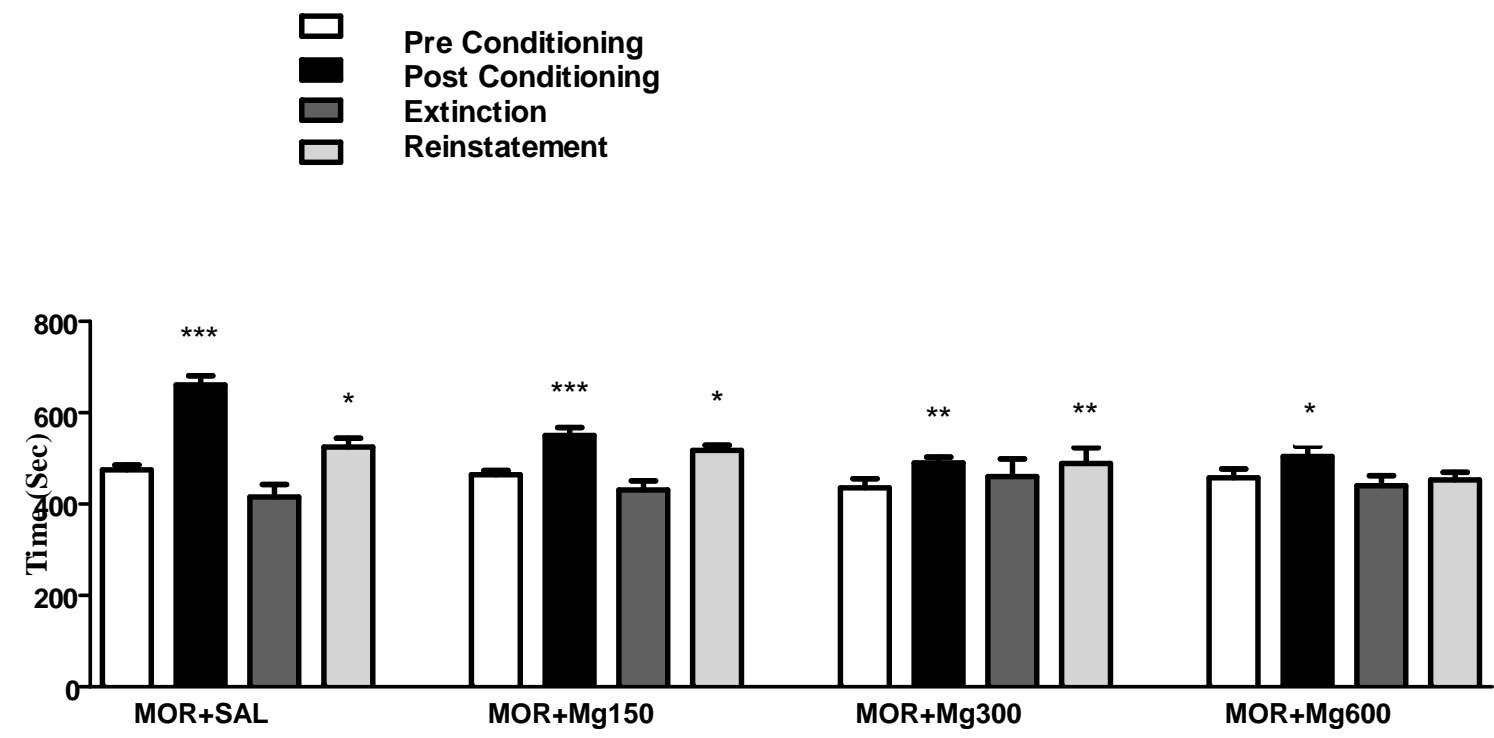

Fig. 2. Effects of magnesium sulfate on the reinstatement of morphine-induced CPP

\section{DISCUSSION}

The current study was carried out in two stages. In the first stage, it was revealed that magnesium sulfate decreased morphine-induced CPP and did not result in morphine tendency or relapse. In the second stage (reinstatement test), 16 days after starting the experiment, magnesium sulfate prevented morphine reinstatement, following the injection of morphine10 mg/kg (the remaining dose).

Many previous studies have shown that morphine $40 \mathrm{mg} / \mathrm{kg}$ can lead to morphine-induced CPP [17-19]. In the current study, about 7 days after starting the experiment, the mice withdrew from morphine if they were put in the CPP apparatus. On the eighth day after starting the experiment, the effects of magnesium sulfate on morphine tendency were evaluated. Following the abstinence-based therapy, injection of morphine $10 \mathrm{mg} / \mathrm{kg}$ on day 16 could reinstate morphineinduced CPP.

Morphine-induced CPP is a complex phenomenon, which involves many systems including opioidergic, dopaminergic, and GABAergic neuronal pathways; many brain regions such as NAcc, VTA, amygdala, and hippocampus are involved, as well [20]. Additionally, one of the most important systems, which contributes to the rewarding effects of morphine, is mesolimbic dopamine system. 
NMDA antagonists can prevent morphine tendency [4, 9, 21]. Magnesium sulfate has NMDA antagonistic effects by preventing calcium entry into the cells from NMDA-receptor channels [22]. In the acute opioid rewarding effects, behavioral and neurochemical sensitization of opioid is related to glutamatergic neurotransmission with dopamine release under the control of glutamate and NMDA receptors [23]. Opioid injection into VTA increases dopamine release in the NAcc [19].

In a study by Robert $\mathbf{J}$ and colleagues, magnesium sulfate potentiated the antinociceptive effects of morphine when administered intrathecally by decreasing calcium entry into the cells and reducing excitatory neurotransmitters in the cortex [24]. Moreover, they found that magnesium sulfate attenuates morphine tolerance and potentiates the antinociceptive effects of morphine [5, $8,24]$. Similar to previous studies, our findings showed that NMDA antagonists can attenuate morphine tendency, tolerance, and dependency [4, 23]. Release of DA in NAcc induces the rewarding effects of morphine addiction [23, 25].

Administration of NMDA antagonist MK 801 potentiates the antinociceptive effects of morphine via blocking calcium influx $[3,5,26]$. Our study was in consistence with previous research on the effects of dextromethorphan on morphine that can alleviate morphine tolerance and dependency [19]. Dextromethorphan is an NMDA antagonist that can potentiate the antinociceptive effects of morphine and decrease morphine tolerance and dependence [19]. In fact, one of the most important mechanisms of hyperalgesia and morphine tolerance is related to excitatory neurotransmitters including NMDA [27].

A previous study showed that memantine, an NMDA antagonist, decreases morphine tendency and morphine-induced CPP [7, 9]. Moreover, self-administration of memantine attenuated the rewarding potential of morphine in a mouse model [21]. Further studies showed that the administration of other NMDA antagonists inhibits the rewarding effects of morphine in CPP models. In fact, activation of NMDA receptors in the NAcc and VTA is necessary for any response that leads to the evocation of morphine's rewarding system [28, 29].

Nitrergic system is more likely to be involved in the magnesium sulfate effects on morphine aversion and inhibition of reinstatement [30]. Magnesium decreases nitric oxide (NO) activity via inhibiting nitric oxide synthase (NOS) [30]. Previous studies have shown that decreasing NO activity reduces morphine-induced CPP in animal models [30, 31]. Similarly, our study showed that another mechanism involved in the effects of magnesium sulfate on morphine withdrawal 
and inhibition of reinstatement is the inhibition of NOS, which leads to a decrease in morphine reinstatement in mice.

In a previous study, the effects of berberis vulgaris aqueous extract on morphine tendency and reinstatement were evaluated. It was revealed that this extract can inhibit morphine tendency and reinstatement presumably by inducing NMDA antagonistic effects [17].

\section{CONCLUSION}

Our results suggest that morphine can strongly block morphine-induced CPP and promote its extinction. In conclusion, it was revealed that magnesium sulfate can be administered for addiction treatment, considering its positive effects on morphine tendency and its suppressive effects on morphine-induced CPP and reinstatement.

\section{ACKNOWLEDGEMENTS}

This study was part of a Pharm. D. thesis, granted by the Research Council of Zabol University of Medical Sciences, Zabol, Iran.

\section{Declaration of interest}

no declaration of interest

\section{Authors'contributions}

The study concept, design, and revision of the manuscript for important intellectual content were done by Mahmoud Hashemzaei and KavehTabrizian. The experiments were carried out by Saeid Keikhah.

\section{Financial disclosure}

We have no financial interests related to the material in the manuscript.

\section{Funding/support}

This study was in part granted by the Vice-Chancellor for Research, Zabol University of Medical Sciences.

\section{References}


[1] Shimoyama M, Shimoyama N, Inturrisi CE, Elliott KJ, Gabapentin enhances the antinociceptive effects of spinal morphine in the rat tail-flick test. Pain. 1997, 72(3):375-82.

[2] Christie MJ, Cellular neuroadaptations to chronic opioids: tolerance, withdrawal and addiction. British journal of pharmacology. 2008, 154(2):384-96.

[3] Advokat C, Rhein FQ, Potentiation of morphine-induced antinociception in acute spinal rats by the NMDA antagonist dextrorphan. Brain Research. 1995, 699(1):157-60.

[4] Ribeiro Do Couto B, Aguilar MA, Manzanedo C, Rodríguez-Arias M, Miñarro J, NMDA glutamate but not dopamine antagonists blocks drug-induced reinstatement of morphine place preference. Brain Research Bulletin. 2005, 64(6):493-503.

[5] Ben-Eliyahu S, Marek P, Vaccarino AL, Mogil JS, Sternberg WF, Liebeskind JC, The NMDA receptor antagonist MK-801 prevents long-lasting non-associative morphine tolerance in the rat. Brain Research. 1992, 575(2):304-8.

[6] Do Couto BR, Aguilar, M.A., Manzanedo, C., Rodriguez-Arias, M. and Minarro, J, Effect of NMDA receptor antagonists (MK-801 and memantine) on the acquisition of morphine-induced conditioned place preference in mice. Neuro-Psychiatry J. 2004, 28:1035-43.

[7] Do Couto BR, Aguilar MA, Manzanedo C, Rodríguez-Arias M, Miñarro J, Effects of NMDA receptor antagonists (MK-801 and memantine) on the acquisition of morphine-induced conditioned place preference in mice. Progress in Neuro-Psychopharmacology and Biological Psychiatry. 2004, 28(6):1035-43.

[8] Kest B, Marek P, Liebeskind JC, The specific N-methyl-D-aspartate (NMDA) receptor antagonist MK-801 blocks U-50,488, but not morphine antinociception. Brain Res. 1992, 589(1):139-42.

[9] Ribeiro Do Couto B, Aguilar MA, Manzanedo C, Rodriguez-Arias M, Minarro J, Effects of NMDA receptor antagonists (MK-801 and memantine) on the acquisition of morphine-induced conditioned place preference in mice. Prog Neuropsychopharmacol Biol Psychiatry. 2004, 28(6):1035-43.

[10] Muir K, Lees K, Ford I, Davis S, Magnesium for acute stroke (Intravenous Magnesium Efficacy in Stroke trial): randomised controlled trial. Lancet. 2004, 363(9407):439 - 45.

[11] Nakashima H, Katayama T, Honda Y, Suzuki S, Yano K, Cardioprotective effects of magnesium sulfate in patients undergoing primary coronary angioplasty for acute myocardial infarction. Circ J. 2004, 68(1):23-8. 
[12] Belfort M, Anthony J, Saade G, Allen J, A comparison of magnesium sulfate and nimodipine for the prevention of eclampsia. N Engl J Med. 2003, 348(4):304 - 11.

[13] Muir K, Lees K, Dose optimization of intravenous magnesium sulfate after acute stroke. Stroke. 1998, 29(5):918 - 23.

[14] Hoffman D, Marro P, McGowan J, Mishra O, Delivoria-Papadopoulos M, Protective effect of $\mathrm{MgSO} 4$ infusion on nmda receptor binding characteristics during cerebral cortical hypoxia in the newborn piglet. Brain Res. 1994, 644(1):144 - 9.

[15] Morris ME, Brain and CSF magnesium concentrations during magnesium deficit in animals and humans: neurological symptoms. Magnesium research : official organ of the International Society for the Development of Research on Magnesium. 1992, 5(4):303-13.

[16] Mees S, Algra A, Vandertop W, van Kooten F, Kuijsten H, Boiten J, van Oostenbrugge R, Salman R, Lavados P, Rinkel G, van den Bergh W, Magnesium for aneurysmal subarachnoid haemorrhage (MASH-2): a randomised placebo-controlled trial. Lancet. 2012, 380(9836):44 - 9.

[17] Imenshahidi M, Qaredashi R, Hashemzaei M, Hosseinzadeh H, Inhibitory Effect of Berberis vulgaris Aqueous Extract on Acquisition and Reinstatement Effects of Morphine in Conditioned Place Preferences (CPP) in Mice. Jundishapur journal of natural pharmaceutical products. 2014, 9(3):e16145.

[18] Almeida-Santos AF, Gobira PH, Souza DP, Ferreira RCM, Romero TR, Duarte ID, Aguiar DC, Moreira FA, The antipsychotic aripiprazole selectively prevents the stimulant and rewarding effects of morphine in mice. European journal of pharmacology. 2014, 742(0):139-44.

[19] Huang EY, Liu TC, Tao PL, Co-administration of dextromethorphan with morphine attenuates morphine rewarding effect and related dopamine releases at the nucleus accumbens. Naunyn-Schmiedeberg's archives of pharmacology. 2003, 368(5):386-92.

[20] Heinrichs SC, Leite-Morris KA, Carey RJ, Kaplan GB, Baclofen enhances extinction of opiate conditioned place preference. Behavioural Brain Research. 2010, 207(2):353-9.

[21] Semenova S, Danysz W, Bespalov A, Low-affinity NMDA receptor channel blockers inhibit acquisition of intravenous morphine self-administration in naive mice. European journal of pharmacology. 1999, 378(1):1-8.

[22] Nechifor M, Chelarescu D, Ciubotaru D, The influence of magnesium on morphine-induced stimulation of the reward system. Magnesium research : official organ of the International Society for the Development of Research on Magnesium. 2010, 23(1):41-7. 
[23] Popik P, Kolasiewicz W, Mesolimbic NMDA receptors are implicated in the expression of conditioned morphine reward. Naunyn-Schmiedeberg's archives of pharmacology. 1999, 359(4):288-94.

[24] McCarthy RJ, Kroin JS, Tuman KJ, Penn RD, Ivankovich AD, Antinociceptive potentiation and attenuation of tolerance by intrathecal co-infusion of magnesium sulfate and morphine in rats. Anesthesia and analgesia. 1998, 86(4):830-6.

[25] Leshner AI, Koob GF, Drugs of Abuse and the Brain. Proceedings of the Association of American Physicians. 1999, 111(2):99-108.

[26] TAGHIZADEH-JAHROMI G, REZAYAT M, ZARRINDAST M, NMDA RECEPTOR ANTAGONISTS ATTENUATE TOLERANCE INDUCED BY MORPHINE AND NERVE LIGATION IN MICE. Medical Journal Of The Islamic Republic Of Iran. 2001, 15(1):41-7.

[27] Mayer DJ, Mao J, Holt J, Price DD, Cellular mechanisms of neuropathic pain, morphine tolerance, and their interactions. Proceedings of the National Academy of Sciences of the United States of America. 1999, 96(14):7731-6.

[28] Hatzigiakoumis DS, Martinotti G, Giannantonio MD, Janiri L, Anhedonia and Substance Dependence: Clinical Correlates and Treatment Options. Frontiers in Psychiatry. 2011, 2:10

[29] Hajnal A, Norgren R, Kovacs P, Parabrachial coding of sapid sucrose: Relevance to reward and obesity. Annals of the New York Academy of Sciences. 2009, 1170:347-64.

[30] Hashemi M, Karami M, Zarrindast MR, Sahebgharani M, Role of nitric oxide in the rat hippocampal CA1 in morphine antinociception. Brain Research. 2010, 1313(0):79-88.

[31] Xiu S, Yuanwu M, E'tang T, Effect of magnesium on nitric oxide synthase of neurons in cortex during early period of cerebral ischemia. Journal of Tongji Medical University. 2000, 20(1):13-5.

\section{How to cite this article:}

Mahmoud Hashemzaei A, Saeed Keykha B, Fatemeh Shahraki C, D. Amirhooshang Mohammadpour D and Kaveh Tabrizian E. Effects of magnesium sulfate on the acquisition and reinstatement of morphine-induced conditioned place preference in mice. J. Fundam. Appl. Sci., 2016, $8(2 S), 112-123$. 